\title{
Touch Tables for Special Collections Libraries: Curators Creating User Experiences
}

This article describes the implementation of touch table technology for McGill University Library's special collections. The touch table was used by the Osler Library of the History of Medicine and the Marvin Duchow Music Library to create audiovisual exhibits to accompany traditional exhibition display cases. Each exhibition curator used a different software platform to create his or her touch table experience. This article explores the introduction of what is now a common technology in museums into the library setting and the attendant challenges, such as the need to create attractive and user-friendly experiences with limited resources and programmer time available. In particular, the article explores the library's choices of software and hardware, providing lessons learned as well as some preliminary recommendations of best practices. It also analyzes the ways in which the touch table has proven to be an excellent addition to the library's exhibition spaces, including its ability to unite disparate resources from multiple branch libraries, to act as a new point of librarian-faculty collaboration, and to display nontraditional items from library collections, such as recorded musical performances and archival video footage.

\section{Introduction}

"Well-curated displays," writes Michelle Maloney in a 2012 article, "can transform 'passive' library collections into communal spaces of discovery, cultivation, and

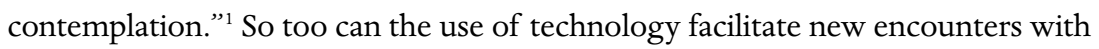
curated materials, creating this sense of cultivation and discovery in public displays. The incorporation of touch table technology into exhibition spaces can add another level of interactivity, allowing visitors to take charge of their own "discovery" and allowing curators to showcase an increased variety of library materials. In July 2015, a project team composed of special collections librarians from multiple branch libraries of the McGill University Library \& Archives acquired an Ideum multitouch table for use in exhibitions of rare materials. The touch table was first used by the Osler Library of the History of Medicine and second by the Marvin Duchow

1. Michelle M. Maloney, "Cultivating Community, Promoting Inclusivity: Collections as Fulcrum for Targeted Outreach,” New Library World 113, no. 5 / 6 (2012): 282, doi:10.1108/03074801211226364.

๑ 2018 by Anna Dysert, Sharon Rankin, and Darren N. Wagner 
Music Library to create audiovisual exhibitions to accompany traditional display cases. Each experience was designed by the exhibition curators and used a different software platform. Open Exhibits, the software recommended by the touch table manufacturer, was used at the Osler Library. The second exhibition, at the Music Library, used IntuiFace, a software selected by the curator. For our purposes, IntuiFace was preferred over Open Exhibits because of the intuitive nature of the IntuiFace composer application, the comparatively short creation time needed to prepare a finished exhibition, and the seamless quality of the user experience created.

This article discusses the vision behind incorporating touch table technology into McGill's special collections and the funding proposal process, as well as the rationale behind the choices of software and hardware, providing lessons learned and some preliminary recommendations of best practices for curators and librarians to create visually pleasing touch table user interfaces in a short amount of time without particular programming or coding skills. This article also analyzes the ways in which the touch table has proven to be an excellent addition to the library's exhibition spaces, including in its ability to unite disparate resources from multiple branch libraries, to act as a new point of librarian-faculty collaboration, and to display nontraditional items from library collections, such as recorded musical performances and archival video footage.

\section{Literature Review}

A now-common museum technology, touch tables are increasingly being imported into the library and being adapted to the needs of this new setting. Museums have long recognized the need to create the most engaging, new, surprising, and seamless exhibition experiences, and ones that also encourage patron involvement and social interaction. ${ }^{2}$ Graham Black notes the high quality of exhibitions that experienced museum-goers expect and the related expectation that they be able and encouraged to participate in and drive their experiences. ${ }^{3}$ Jennifer L. East refers to these aspects as the "independent sense-making and collective discussion about... experiences with exhibits." For all of these reasons, the "technological invisibility" of multitouch tables has drawn museum creators to the tool. There is a significant amount of literature on touch tables as exhibition tools in museums, science centers, and heritage institutions such as The Hive, a heritage center attached to a

2. Studies on use of multitouch tables in museums are now numerous; see, for example, Tom Geller, "Interactive Tabletop Exhibits in Museums and Galleries," IEEE Computer Graphics and Applications 26, no. 5 (2006): 6-11, doi:10.1109/MCG.2006.111.

3. Graham Black, The Engaging Museum: Developing Museums for Visitor Involvement (New York: Routledge, 2005).

4. Jennifer L. East, "An Exploratory Study on Family Group Use of a Multi-Touch Table Exhibit at a Public Marine Science Center" (MSc thesis, University of Oregon, 2015), available online at http://hdl. handle.net/1957/57119 [accessed 26 September 2017]. 
university. ${ }^{5}$ These studies include closely investigating the use of gesture and touch in multitouch technology and surveys of patron interaction with large displays. ${ }^{6}$

The use of touch tables in libraries is a more recent development, yet studies suggest that touch tables are already serving a variety of purposes in those settings. For example, touch tables are in some cases found in maker spaces or student production spaces, like the Digital Media Commons at the University of Calgary's Taylor Family Digital Library (TFDL), which has five touch tables for faculty and student use. Clarke and Hoffman describe their uses: "Two of the permanently stationed touch tables are located in high profile areas on the first two floors of the TFDL and students are encouraged to display their artwork, research or even their graffiti (!) on the media wall to which the tables are connected."' The University of Michigan's Duderstadt Center Digital Media Commons also uses touch tables to display student and faculty research: "These are relatively large-scale devices that allow you to interact with them through touch, rather than through a keyboard, mouse, or other external device. Even more interesting is that they allow you to use both hands, as well as gestures." ${ }^{8}$ Touch tables are also found in libraries for interactive room booking systems, digital signage, and other wayfinding purposes. ${ }^{9}$

In the context of library historical collections, libraries have invested in touch tables to improve the usability of historic objects, sometimes in the context of teaching, as a touch table allows an entire class to interact with digital surrogates of a particular book in a way that is not possible with the small physical object itself; or, alternatively, the format of the object is so large that it cannot be used easily. ${ }^{10}$

5. Chris Creed, Joseph Sivell, and John Sear, "Multi-Touch Tables for Exploring Heritage Content in Public Spaces," in Visual Heritage in the Digital Age, eds. Eugene Ch'ng, Vincent Gaffney, and Henry Chapman (London: Springer London, 2013), 67-90, doi:10.1007/978-1-4471-5535-5_5.

6. Uta Hinrichs and Sheelagh Carpendale, "Gestures in the Wild: Studying Multi-Touch Gesture Sequences on Interactive Tabletop Exhibits," in Proceedings of the SIGCHI Conference on Human Factors in Computing Systems (ACM, 2011): 3023-32, doi:10.1145/1978942.1979391; Carmelo Ardito, Paolo Buono, Maria Francesca Costabile, and Giuseppe Desolda, "Interaction with Large Displays: A Survey,” ACM Computing Surveys 47, no. 3 (Feb. 2015): 46.1-46.38, doi:10.1145/2682623.

7. Kim Clarke and Nadine R. Hoffman, "It's All about the Technology," Canadian Law Library Review 37, no. 2 (2012): 70, available online at http:/ / heinonline.org/HOL/Page?handle=hein.journals/ callb37\&g_sent $=1 \&$ casa_token $=\&$ collection $=$ journals $\& i d=73$ [accessed 21 November 2017].

8. P.F. Anderson, "Connecting Libraries, Makerspaces, Data Visualization, \& Innovation, Part Two," Emerging Technologies Librarian (blog), June 27, 2013, available online at https: / / etechlib.wordpress. $\mathrm{com} / 2013 / 06 / 27 /$ connecting-libraries-makerspaces-data-visualization-innovation-part-two [accessed 21 November 2017].

9. "Digital Signage in the Libraries," Stanford Libraries Blog (blog), January 15, 2014, available online at http: / /library.stanford.edu/blogs/stanford-libraries-blog/2014/01/digital-signage-libraries [accessed 21 November 2017].

10. For example, Eugene Ch'ng, "The Mirror between Two Worlds: Multitouch-Multiuser Interaction for 3D Digital Objects and Environments," in Digital Media and Technologies for Virtual Artistic Spaces, ed. Dew Harrison (Hershey, Pa.: IGI Global, 2013), 166-85, available online at https:/ / ebookcentral. proquest.com $/ \mathrm{lib} / \mathrm{mcgill} /$ detail.action?docID $=3312344$ [accessed 1 December 2017]. 
Brown University has used a touch table for providing access to a nineteenth-century, 273-foot-long, double-sided, watercolored panorama by Garibaldi. ${ }^{11}$

Touch tables are increasingly and perhaps primarily found in special collections as a complement to traditional exhibitions or as standalone exhibitions. Part of the appeal of the touch table as referenced in the literature is the idea of the attractive marriage of old and new: representing old materials, in both the sense of conventional or historic formats as well as old in age, in digital form to add a new layer of interaction and interpretation. A second idea is that of sparking conversation; as Lora Baiocco notes in an article on the use of the Doklab's Local Stories software and a multitouch table at the Westmount Public Library in Quebec, "the table will be placed in a high-traffic area where conversation will be encouraged." 12 The idea of touch tables as a point of gathering and interaction not only with the objects but with other viewers is also expressed by the curators of exhibitions at the Library of Birmingham: "it was decided that it should encourage discussion between multiple users and be a starting point for conversations with library staff instead of being a single-user research tool." ${ }^{\prime 13}$ At Boston University, special collections librarians have explored touch tables "as potential complements to future physical and digital exhibitions and as potential showcases of digital library collections." ${ }^{14}$ In the fall of 2016, two touch tables were placed in library lobbies to "engage students, display digital content, and provide new ways to introduce, exhibit and teach with materials digitally." 15 One table was used to display photographs of student life on campus, and the second table provided access to a digital reproduction of a fourteenthcentury music manuscript, the Burns antiphoner sanctorale, a Franciscan liturgical book, plus new research and data. ${ }^{16}$

11. Brown University, “The 21st Century Library: The Garibaldi Panorama," filmed Oct. 2010, YouTube video, 02:50, posted Oct. 4, 2010, available online at https: / www.youtube.com/watch?v=vpsQpltGol4 [accessed 8 December 2017].

12. Lora Baiocco, "Labor of Love: Opening Up Archival Gems for Community Engagement," Computers in Libraries 36, no. 4 (2016): 4-5, available online at http:/ / www.infotoday.com/cilmag/may16/ Baiocco--Labor-of-Love--Opening-Up-Archival-Gems-for-Community-Engagement.shtml [accessed 8 December 2017].

13. John Sear, "65" Touch Table Library of Birmingham," John Sear, Builder of Magical Collaborative Experiences for Public Spaces (blog), Mar. 17, 2014, available online at http://johnsear.com/65-touch-tablelibrary-of-birmingham [accessed 15 September 2017].

14. "Multi-Touch Tables," BCDIGSCHOL (Boston College Digital Scholarship wiki), 2014, available online at https: / / bcdigschol.hackpad.com/Multi-Touch-Tables-7kcrMW5Q83b [accessed 8 December 2017].

15. Anna Kijas, "Multi-touch Tables Offer a New Way to Experience Our Materials," Boston College Libraries Newsletter (Fall 2016), available online at https:/ / library.bc.edu/newsletter/?p=169 [accessed 8 December 2017].

16. "Burns Antiphoner," Boston College Libraries (2017), available online at http:/ / burnsantiphoner. bc.edu/ [accessed 1 December 2017]. 


\section{Overview of Special Collections Exhibitions at McGill University}

McGill University Libraries is a system of thirteen branch libraries, including one library devoted wholly to Rare Books and Special Collections, ${ }^{17}$ four libraries that hold and provide access to rare and special collections in addition to circulating materials and the University Archives. As such, there are multiple exhibition spaces associated with the collections, each library containing exhibition space of varying sizes, constructed of various materials and generally positioned in central lobby areas. The McGill special librarians curate and schedule their exhibitions individually, to suit their needs, and collaborate informally, sharing collections and expertise as needed.

Located in the central Humanities and Social Sciences Library, the department of Rare Books and Special Collections (RBSC) holds items relating notably to Canadian literature, history, maps, travel, and popular culture; Enlightenment philosophy; English and French literature of the eighteenth century; book and printing history; the Olympics; and cookery. Public exhibition programming is a central part of RBSC outreach, and exhibitions change four times a year. In the main lobby of the Humanities and Social Sciences Library, there are three freestanding custom-built flat display cases. On the fourth floor, next to the RBSC reading room, there are additional flat cases, as well as upright wall cases. Inside the RBSC reading room, there are an additional eight smaller cases that run contiguously throughout the space and allow for both flat viewing of materials and wall-mounted items. ${ }^{18}$

Exhibitions are also a primary activity of the Osler Library of the History of Medicine, where staff, in collaboration with student or professor guest curators, install new public exhibitions three to four times a year. The Osler Library opened in 1929 with the donation of the personal library of Sir William Osler, the Canadian physician and McGill alumnus who had assembled an 8,000-volume collection of rare medical and scientific works. The collection has grown to around 100,000 titles representing the history of the health sciences and medical practice. ${ }^{19}$ The Osler Library's main exhibition space features two flat cases and two wall-mounted cases.

17. “About Rare Books and Special Collections," McGill University Library \& Archives, available online at https://www.mcgill.ca/library/branches/rarebooks/about [accessed 12 December 2017].

18. Sean Swanick, Sharon Rankin, and Melinda Reinhart, "Curating Exhibitions in Academic Libraries: Practical Steps," Practical Academic Librarianship: The International Journal of the SLA Academic Division 5, no. 2 (2015): 1-22, available online at https://journals.tdl.org/pal/index.php/pal/article/view/7011 [accessed 20 July 2017].

19. "Bibliotheca Osleriana," in Meeting with Books: Special Collections in the 21st Century, with a Tribute to Raymond Klibansky \& Illustrated Survey of Special Collections at McGill University Library and Archives, eds. Jillian Tomm and Richard Virr (Montreal: McGill University Library and Archives, 2014) available online at http:/ / digitool.Library.McGill.CA:80/R/-?func=dbin-jump-full\&object_id=1289168silo_ library=GEN01 [accessed 4 April 2018]; "About the Osler Library of the History of Medicine," McGill University Library \& Archives, available online at https: / /www.mcgill.ca/library/branches/osler/about [accessed 1 December 2017]. 
The last three libraries that feature both circulating material and rare material and operate a public exhibitions program are the Islamic Studies Library, the Marvin Duchow Music Library, and the Nahum Gelber Law Library. The special collections of the Music Library include original manuscript scores and personal correspondence of such twentieth-century composers as Marvin Duchow, Julius Schloss, and Kelsey Jones; the papers of music critic Eric McLean; and many historical vocal scores of prominent provenance, as well as eighteenth- and nineteenth-century study and performing editions of French and German repertoire. ${ }^{20}$ The Music Library curates several exhibitions per year, usually in conjunction with the Schulich School of Music programs and events. The exhibition space is limited to two small, secure wall cases adjacent to the library entrance and wall spaces on three internal library floors. The Islamic Studies Library curates roughly two exhibitions per year in its tall, freestanding, Gothic-style exhibition cases. Past exhibitions have highlighted Islamic manuscripts, calligraphy, and science. The Law Library's Wainwright collection contains French Civil Law material from the personal library of the French legal historian François Olivier-Martin and special collections containing early Canadian, British, and American titles. ${ }^{21}$ The Law Library prepares several exhibitions each year in a pair of floor cases in the library lobby as well as two wallmounted cases adjacent the library entrance.

\section{A Vision for Touch Tables in Special Collections}

Special collections librarians from the five branches described above conceived of a project to incorporate touch table technology into exhibition spaces. The original project proposal was wide-ranging in its vision for the incorporation of a touch table into special collections to allow librarians to facilitate new types of access to rare materials for classes, visitors, and researchers. Special collections are charged with protecting the documentary witnesses of our cultural and intellectual heritage, but protecting these items means very little without providing access as freely as possible. ${ }^{22}$ In addition to exhibitions, the group description highlighted teaching as another benefit of the touch table as a way of bolstering the teaching and learning experience of the many classes that rely on McGill's rare resources. As book history has become over the last two decades an important, even core, methodology for historical and literary studies, professors are seeking new teaching practices based on substantial and challenging intellectual encounters with primary sources. Special collections librarians are moving beyond the "show and tell" model of class

\footnotetext{
20. "Music Special Collections," McGill Library Subject Guides, McGill University Library \& Archives, available online at https://www.mcgill.ca/library/find/subjects/music/special/ [accessed 12 December 2017].

21. "About the Nahum Gelber Law Library," McGill University Library \& Archives, available online at www.mcgill.ca/library/branches/law/about [accessed 13 December 2017].

22. E. Haven Hawley, "Reflections on the Meanings of Objects," in Forging the Future of Special Collections, eds. Melissa A. Hubbard, Robert H. Jackson, and Arnold Hirshon (Chicago: Neal-Schuman, 2016), 3-20.
} 
teaching and instead supporting professors seeking to incorporate close readings of books and other textual artifacts into learning. Recent research has indicated that "multi-touch wall displays can support different collaboration styles and fluid transitions in group work." ${ }^{23}$

The incorporation of close and individual interactions with historical materials is another aspect that appeals to curators when integrating touch screens into exhibitions. A touch table or touch screen allows librarians and curators to add both additional items beyond what physical space permits us and interactive elements to exhibitions. Interactive elements could include, for example, filmed walk-throughs with exhibit curators, behind-the-scenes videos on how certain books were constructed, digital surrogates of other media (such as photographs, slides, and videos), renderings of 3D spaces, born-digital works, and so forth.

The McGill project group was also originally interested in the possibility of having touch tables available for the benefit of researchers. The significant amount of magnification permitted by the touch table plus the ability to manipulate multiple images at once make it a tool that would be highly appreciated by several researchers working with rare materials. Some examples include bibliographers whose work involves identification of microscopic details of printing and paper, or medieval manuscript specialists whose work involves comparison of tiny details of letterforms to identify the date and location of a manuscript's creation. The work of collation, for example (the comparison of copies of the same printed text), could also be greatly facilitated by the touch table not only because it allows comparison of multiple copies at once on one screen but, because it works with digital surrogates, it would be possible to compare a copy of a text from the Osler Library with texts from all over the world, as if side by side.

\section{Piloting the Innovation Proposal: Two Case Studies}

The Touch Tables for Special Collections Libraries proposal submitted in July 2015 requested the purchase of four touch tables and was awarded funds to implement one table as a pilot project. An exhibition currently in preparation at the Osler Library was chosen as the initial pilot project in which to test out the technology. The exhibition was chosen in some part because of the serendipity of timing; in addition, the curators (two postdoctoral researchers specializing in the history of medicine) had already expressed their desire to integrate a range of materials including rare books, medical instruments, projected film, mounted images, and video footage into their exhibition design. The project group instantly recognized

23. Mikkel R. Jakobsen and Kasper Hornbæk, "Up Close and Personal: Collaborative Work on a High-Resolution Multitouch Wall Display," ACM Transactions on Computer-Human Interaction (TOCHI) 2, no. 2 (2014): 1-34, doi:10.1145/2576099. 
that the availability of a touch table would help realize this level of ambitious exhibition curation. The guest curators' relative comfort and ease with computing and technology was also an asset and factored into the decision.

Project funds were used to purchase the Ideum touch table and motorized stand, four headphones, and an educational-discounted IntuiFace Composer and Player license for one year. A professional moving company that often works with the university was contracted to transport the table in its shipping crate between branch libraries. A motorized lift transformed the touch table into a presentation display screen or touch wall. Ideum (http:/ / ideum.com) provided a turnkey solution, including a Form factor (16G RAM) computer, two 15-watt Dolby surround sound speakers, Wi-Fi and Ethernet connection, preloaded with several Windows educational apps, two-year warranty and customer support. This touch table hardware configuration is in use at many U.S. academic institutions, but not in any Canadian Association of Research Libraries (CARL) libraries that could be identified.

\section{Case Study: Knowing Blood / Sang sens Exhibition}

The initial project for McGill Library's touch table was the exhibition Knowing Blood: Medical Observations, Fluid Meanings / Sang sens: observations médicales, interprétations fluides. ${ }^{24}$ This bilingual exhibition explored the fundamental role of observation in shaping the medical meanings of blood between the late fifteenth and late twentieth centuries. Co-curated by Darren N. Wagner and Nick Whitfield and hosted at the Osler Library of the History of Medicine, the exhibition ran from January to August 2016. Displays with rare books and objects highlighted different historical approaches to medical observation, blood's relation to changing medical practices, and the broader social meanings of blood.

In its original conception, Knowing Blood was to include a projection of twentiethcentury archival medical films. The curators were investigating the logistics of projecting these films within the exhibition space when, fortuitously, the opportunity arose to trial-run the Ideum touch table. The advantages of showing films on the touch table rather than with a projector are several: less required space, greater scope for curating user experience, and the possibility of showcasing different kinds of digital material. Although both Wagner and Whitfield were familiar with designing museum exhibits, neither knew much about setting up an interactive touch table display. This learning process was related in Wagner's report to the library in the summer of 2016 :

24. Anna Dysert, "New Exhibition: Knowing Blood / Sang sens," De re medica: News from the Osler Library of the History of Medicine (blog), Jan. 21, 2016, available online at https: / blogs.library.mcgill.ca/ osler-library/new-exhibition-knowing-blood-sang-sens/ [accessed 24 August 2017]. 
Dr. Whitfield and I originally envisioned using the touch table to display multimedia items categorized by five themes corresponding to the exhibition's five display cases. Our aim was to expand the exhibition's parameters through extra materials that provided more cultural and social context to the medical history on display in the cases.

I took it upon myself to program the touch table; I am not, however, a trained or seasoned programmer. It seemed sensible to use the software created in conjunction with Ideum called Open Exhibits, especially as this was the first run with the touch table. ${ }^{25}$ This freeware is installed easily from their website, comes with web support, and is programmable using Creative Markup Language (CML), and offers simulation options for coding on personal computers without touchscreen capabilities. I worked my way through their tutorials and, after many trial-and-error attempts, achieved a workable exhibit. The Open Exhibits platform is somewhat restricted in its capacity, and coding using CML is finicky. I ended up with a pared-down version of our original vision: twelve video and audio files that visitors can watch and hear using headphones. However, we think these multimedia items complement the exhibition very well.

Even with a smaller experience than was initially hoped for, the touch table was deemed an excellent complement to the exhibition's more conventional displays of books and objects (see figure 1). These multimedia resources, which ranged from approximately three to thirty minutes, gave the exhibition an added layer of richly interactive audio and video components. Yet, as shown by Gido Albert Hakvoort's research on multitouch technologies in exhibitions, the presence of interactive tables decreases the time visitors spend engaging with artifacts. ${ }^{26} \mathrm{~A}$ better design of the Knowing Blood touch table display would feature more cues guiding visitors to view specific objects in the display cases.

Most of the curators' frustrations and criticisms regarding the touch table stemmed from the Open Exhibits software. There were several problems in using that platform: limitations in designing the layout of the home screen (see figure 2), insufficient user controls for the multimedia files (there were no fast-forward or rewind functions), the touch control was too sensitive for some gestures (a problem that could only be remedied with added coding in Gesture Markup Language), and an inability to use accents for French script in CML. More troubleshooting and coding

25. "About Open Exhibits," Open Exhibits, available online at http://openexhibits.org/about/ [accessed 14 December 2017].

26. Gido Albert Hakvoort, "Multi-Touch and Mobile Technologies for Galleries, Libraries, Archives and Museums" (PhD thesis, University of Birmingham, 2016), 150, available online at http://etheses. bham.ac.uk/6901/ [accessed 23 August 2017]. 
work could fine-tune some of these glitches and shortcomings. Yet it is evident that using the Open Exhibits SDK 4.1 software is limited and troublesome, especially for someone unfamiliar with coding CML.

While a touch table is an ideal tool for making digital and online resources readily available to visitors, it has some logistical and aesthetic shortcomings for showing films. Watching historical films that are projected seems a more authentic and
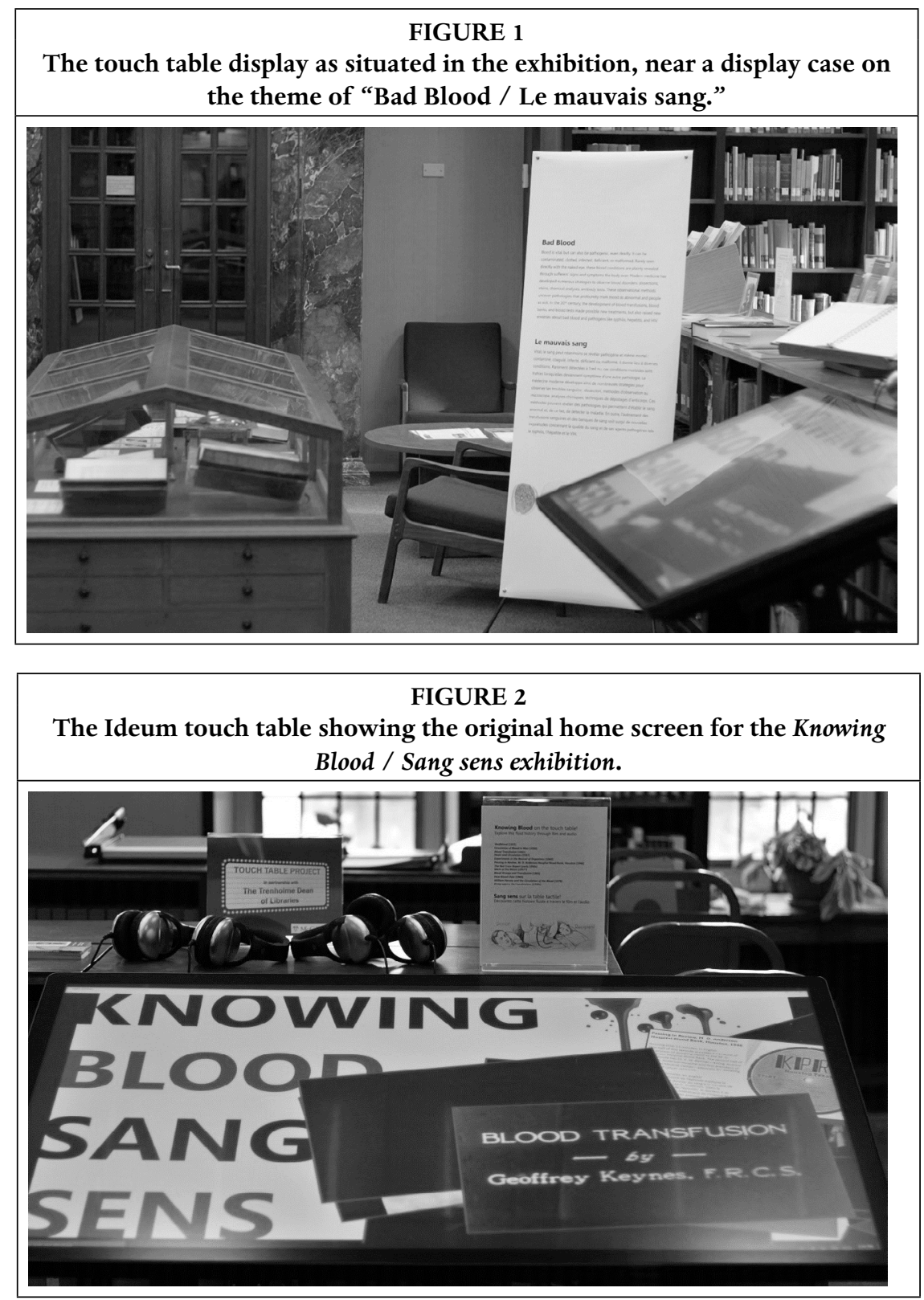
engrossing experience. With the touch table, the viewer tends to crowd close to the screen, poised to actively browse, select, and manipulate. For simply viewing films, the vast digital capacity of the touch table verges on technological overkill.

\section{Case Study: John Rea's Musical Universe and Hubert Bédard and Hellmuth Wolf: Visionaries of the Early Keyboard Revival}

The second project for McGill Library's touch table was a combined experience for two Music Library exhibitions: John Rea's Musical Universe and Hubert Bédard and Hellmuth Wolf: Visionaries of the Early Keyboard Revival. ${ }^{27}$ The John Rea's Musical Universe exhibition was created to celebrate this Montreal composer and former Dean of the Schulich School of Music at McGill University. For this experience, we experimented with displaying and connecting to works by John Rea, whose format did not lend themselves to display in a traditional wall case. When this exhibition was selected from the touch table menu by the user, the opening scene automatically played an autobiographical YouTube video of the composer. The user was presented with other supplementary options: web pages of John Rea's 2016 concert season, YouTube videos of other productions, or selections of John Rea's scholarship published in music electronic journals.

The Hubert Bédard and Hellmuth Wolf: Visionaries of the Early Keyboard Revival exhibition was created by the Music Library staff to coincide with the 2015 International Conference of the Historical Keyboard Society of North America held at the Schulich School of Music in May 2015. ${ }^{28}$ This exhibition celebrated the archival collections of two Canadian musicians who set new standards for the building and restoring of historical keyboards. Hubert Bédard was devoted to the restoration and construction of harpsichords modeled on original prototypes of Flemish and French keyboards. Hellmuth Wolff was a master organ builder of mechanical traction organs in the province of Quebec. In its physical exhibition, the library was able to display selected workshop objects, tools, photographs, and scores: items small enough in size to fit into its wall exhibition case. Color selections from Hellmuth Wolff's organ plans and photographs were digitally reproduced at 600 dpi, professionally printed on foam core and formed an impressive set of wall posters. This exhibition was complemented by a carousel of the wall poster images on the touch table. Each image could be enlarged and moved about, enabling the user to see the plan detail (see figure 3). Each poster's case card displayed when a user

27. "Exhibition: Hubert Bédard and Hellmuth Wolff: Visionaries of the Early Keyboard Revival," McGill University Library \& Archives Events Channel, May 27, 2015, available online at https: / www.mcgill. $\mathrm{ca} /$ library/channels/event/ exhibition-hubert-bedard-and-hellmuth-wolff-visionaries-early-keyboardrevival-252994 [accessed 15 December 2017].

28. "2015 International Conference of the Historical Keyboard Society of North America," Historical Keyboard Society of North America, available online at http:/ / historicalkeyboardsociety. org/2015-hksna-conference-at-mcgill-university-montreal-canada/ [accessed 20 September 2017]. 
rotated the carousel to select an image. For this experience, audio files played an organ concert, recorded on the Wolff \& Associés, Opus 24, 1981 in McGill's Redpath Concert Hall. ${ }^{29}$ The exhibitions also contained links to the web surveys designed by the curators to collect user experience feedback.

29. "Université McGill University, Salle Redpath Hall, Montréal, Qué. Wolff \& Associés, Opus 24, 1981," Orgues au Québec/Organs in Québec, available online at www.musiqueorguequebec.ca/orgues / quebec/redpath.html [accessed 24 September 2017].
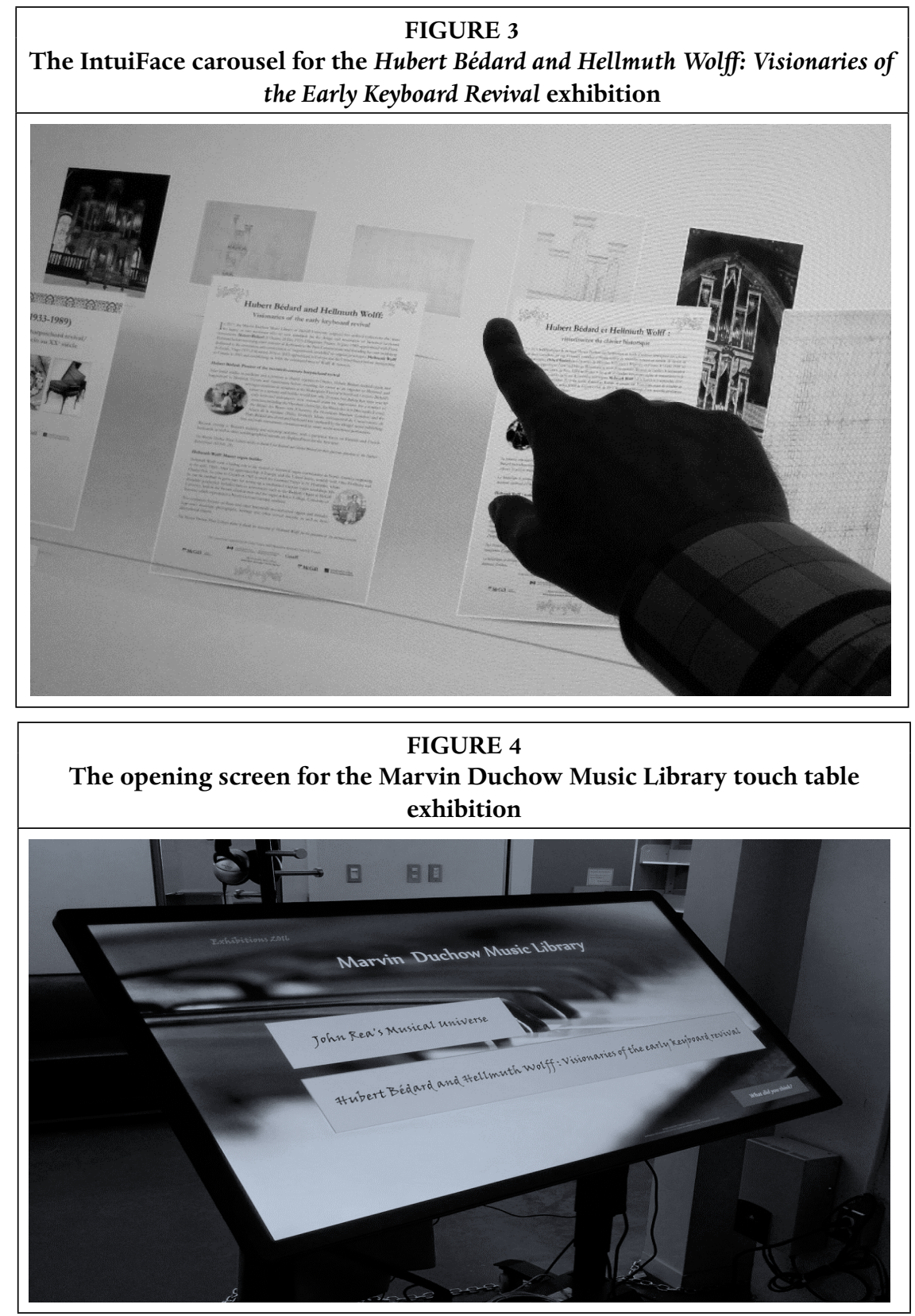
Both touch table user experiences were created using IntuiFace software from Intuilab, a company headquartered in France whose mission statement, "to offer a software platform - IntuiFace - to empowering anyone, of any skill set and in any business, to create and deliver gratifying and purposeful interactive and connected experiences on multiple devices, in record time and without coding software," is an apt and accurate description..$^{30}$ The Music Library curator, Rankin, a librarian with limited technical skills and no programming capabilities, was able to build the user experience in IntuiFace within a very short time frame. After working through the company's online tutorials, the curator created scenes, selected asset types to control the digital object displays, configured their properties, and created event triggers to link user touches to specific actions in the experience, all within the IntuiFace Composer software. The Composer provided the curator complete control over choice of color palette, font, background images for each scene, and display properties of the digital objects. The system is designed to allow the curator to create the experience on a computer other than the touch table. From within the IntuiFace Composer, it is possible to run the IntuiFace Player to see how the experience will look and react to user interaction. The completed experience was published in the Intuilab cloud and remotely deployed to the touch table, whose IntuiFace Player software will run the experience.

The pilot project was successful from both the user and creator perspectives. The Music Library received very positive feedback about the experience. The time invested to learn the IntuiFace platform was repurposed by the curator, who went on to create several subsequent special collections exhibitions in 2016.

\section{Lessons Learned}

\section{IntuiFace as the Software of Choice}

Since the summer of 2016, beginning with the Music Library's John Rea's Musical Universe, McGill special collections librarians and staff have created twenty touch table experiences in IntuiFace and seven are currently on the schedule for the 2018-2019 academic year. This statistic alone is a testament to the success of the platform and its ease of use. The first pilot exhibition Knowing Blood / Sang sens was reworked by Rankin and Wagner into IntuiFace and was used in September 2016 during Science Literacy Week. Interestingly, in the lessons learned paper describing the Hive project (the first integrated public/ university library and history center in Europe), the authors surveyed the variety of programming languages available for creating multitouch applications and include Open Exhibits, referring to it as a "multi-user toolkit...includ[ing] over 50 different customisable user interface components making it easy to efficiently develop applications without much tech-

30. "About-Company," IntuiLab, available online at https://www.intuilab.com/company [accessed 13 December 2017]. 
nical expertise. For instance, it is feasible for a technical museum curator to create their own exhibits by plugging together these components without any developer assistance." ${ }^{31}$ The Open Exhibits experience at our campus provided evidence that curators do need technical expertise to create good touch table exhibitions, so we recommend choosing a commercial product like IntuiFace, which has reasonable educational pricing. The Hive experience was eventually custom-built with Microsoft Surface SDK, a software that allowed the developers to provide all the required functions.

McGill Library currently has four staff members (three librarians and one digitization administrator) trained to use IntuiFace. We would like to grow this capacity for several reasons, most notably to provide the opportunity for all special collections librarians to create and complete an experience from start to finish, allowing them both to have the highest level of curatorial control over digital exhibitions and the knowledge to work in collaboration with faculty or student co-curators. Our pilot project received a Year Two round of funding, enabling a purchase of a second Ideum touch table; and, with additional support from McGill undergraduate students, we now have a third Ideum touch table as of the fall of 2017, so we have technology to grow our special collections exhibitions on touch tables across all of the McGill libraries.

\section{Share and Share Alike}

Of economic interest to libraries is the fact that it has not proven necessary to have touch tables in every branch in the context of exhibitions programming. Instead, the project team created specialized documentation on the shared staff intranet to centralize scheduling. Within the first semester of its implementation alone, the touch table was in high demand, with four different libraries signing on to use it in creating digital exhibition experiences. The touch table exhibition schedule on the library's intranet has become increasingly important and effective at ensuring the tables are assigned where they are needed and experiences created in time. What began as an ad hoc group of knowledgeable curators and library staff has now been formalized into a working group to share expertise, discuss scheduling, document best practices, and review each exhibition's specifications to see if outcomes are feasible.

On a campus with multiple library branches (some larger and more central, others quite small and specialized), the touch table also adds to a feeling of a cohesive library whole. Touch table experiences have been created with the goal of not just enhancing traditional exhibitions in situ, but also being able to function as small

31. Creed, Sivell, and Sear, "Multi-Touch Tables for Exploring Heritage Content in Public Spaces," 3-4. 
standalone mini-exhibitions that can be used in various locations. For example, the touch table component to the Knowing Blood / Sang sens exhibition was, after being reworked in IntuiFace, used in another library location as part of the central library's Science Literacy Week programming. In this way, students, visitors, and faculty can discover and experience a fuller range of library materials without traveling to one of the smaller and less-frequented branches. The touch table also provides an easy way for materials from other branches to be digitized and used in exhibitions, encouraging sharing between units and promoting discovery for users.

\section{Consider Logistics}

The geographical distances between the branch libraries posed a transportation problem. How could we move the touch table secured on its motorized stand, safely between buildings and campuses? The second round of funding provided a solution, at which point we were able to purchase an Ideum Air Transit Approved (ATA) road case, equipped with ramp and wheels. Though often too large to enter library lobbies, the ATA case protects the touch table during transit, ensures that it arrives to its destination in good working order, and reduces the time and number of library staff involved in each move.

Given the attractiveness and value of the library's touch tables, we have explored three avenues of physical security. The motorized stand is on wheels, which adds to its convenience in traveling between locations. However, it does make it possible to potentially remove a touch table when the library is open without staff, which is the case for some libraries with extended study hours. When a library has 24-hour security presence during opening hours, we have left the table unsecured. We initially purchased a security chain/wire and various locks that can be used for a temporary location. For a permanent location, we have secured the touch table to a bolt in the adjacent wall. (This option is not ideal because the table can no longer be used horizontally.)

The touch table allows librarians to stage pop-up exhibitions in any library without the physical constraints of display cases, display space, and lighting. All the touch table needs is electricity, and with wireless internet even an Ethernet connection is not required.

\section{Growing the Experience}

As we have created each new experience and our knowledge of the interface grows, we were able to further explore advanced aspects of the IntuiFace platform. For example, we were able to create a special collections exhibit with all of the digital objects and their associated metadata living outside the IntuiFace platform. The Excel Interface Asset (IA) allows the experience to read from Microsoft Excel 
spreadsheets containing image locations and descriptive text. IntuiFace displays the content from the provided Excel spreadsheet. ${ }^{32}$ Updating the exhibition and keeping content fresh and accurate are greatly facilitated by this feature.

\section{Remote Management of the Experiences}

The Intuiface platform has various licensing levels related to functionality that can be selected to accommodate needs. The Composer level that we have purchased includes the functionality of remote management of experiences. The administrator console can view each touch table, see what experience is running, restart an experience on a specific touch table, or select another experience to run on a specific touch table. This ability to administer the experiences remotely across the library is invaluable and allows the touch tables to be managed by a single library staff member.

\section{Assessment}

The touch table project team was originally interested in determining whether the addition of a touch table to a conventional exhibition increased users' engagement with and enjoyment of their experience as compared to an analogue exhibition. Librarians designed a survey using Survey Monkey to collect information about users' exhibition experiences as the first step in an assessment plan. Due to a lack of response, the results collected were not informative. Instead, with the change of software, the decision was made to use the data-tracking features provided by the IntuiFace platform. With one setting, the curator engaged the automatic tracking of movement between scenes and length of time spent on each scene. This real-time tracking of event information is sent directly to a centralized, cloud-based Hub, and the data are easily accessed with Excel. Additional triggers were added for specific movements in the exhibition so that this activity could be logged. A blank text box that can be edited by users was also implemented to serve as a feedback form or visitor's guest book to capture exhibition comments.

\section{Touch Table Position and Engagement}

The motorized stand on each of the touch tables allows the position of the screen to be set to anywhere from vertical to horizontal. For the exhibitions to date, we have placed the screen diagonally, at a 45-degree angle, a position we assumed provided users maximum comfort for viewing and interacting with the touch screen. Ardito et al. note in their work on interaction with large displays that a touch table's angle has an effect on its perceived usage and what types of user interactions it encourages. For example, a diagonal display such as ours is optimal for viewing,

\footnotetext{
32. "Knowledge Base: Interface Asset-Excel," IntuiFace Support (2017), available online at http:// support.intuilab.com/kb/interface-assets/interface-asset-excel [accessed 15 December 2017].
} 
but it does not encourage gathering around the display in collaborative ways. ${ }^{33}$ The authors note that "collaboration is better supported by both horizontal and vertical displays. The former allows several possibilities for user arrangement, also providing a flat surface for placing objects. The latter gives all viewers the same perspective of the task and provides a holistic view of the data." ${ }^{34}$ Hinrichs and Carpendale have also observed that "a vertically mounted screen attracted attention, but this also made people feel anxious and uncomfortable as others could [publicly] observe what they were doing." ${ }^{35}$ The choice of positioning should thus be considered when designing a display and thinking about the desired kind of user interaction. It should also be taken into account when assessing or observing user response to the experiences. Perhaps as a result of our favoring a diagonal position for optimal reading, our anecdotal evidence, from watching users interact with the surface, has revealed that most users are using one single touch in their interaction. The Ideum touch table has eighty multitouch points, which our current experiences are not yet employing. This indicates perhaps that users are using the experiences individually rather than as shared interactions.

Additional studies "in the wild" will need to be undertaken, so we can better understand how users are engaging with the touch table. ${ }^{36}$ Future experiences, especially on the student-funded table, will use the touch screen positioned horizontally, running experiences that encourage multitouch.

\section{Promoting a Collaborative Service Model}

As the touch table has become a recognized part of the library's offerings, we have endeavored to frame the creation of a touch table experience as a point of collaboration for librarians and academic faculty and researchers. Library exhibitions have a variety of goals and philosophies behind them; often they serve as part of library outreach or promotional efforts, but they are also often a scholarly product in themselves, either on the behalf of knowledgeable librarians, librarians and faculty/student collaborators, or librarians supporting faculty member or student exhibitions. Special collections librarians have an interest in promoting exhibitions partnerships, either as co-curators or as curatorial support, to increase collaboration between libraries and faculties and increase student and faculty investment in the library and its collections. The touch tables at McGill have encouraged fruitful partnerships between librarians with the technical and digital curatorial expertise

33. See also William Buxton, George Fitzmaurice, Ravin Balakrishnan, Gordon Kurtenbach, "Large Displays in Automotive Design," IEEE Computer Graphics and Applications, 20 no. 4 (July 2000): 68-75, doi: $10.1109 / 38.851753$.

34. Ardito, Buono, Costabile, and Desolda, "Interaction with Large Displays," 11.

35. Uta Hinrichs and Sheelagh Carpendale, Interactive Tables in the Wild-Visitor Experiences with MultiTouch Tables in the Arctic Exhibit at the Vancouver Aquarium, University of Calgary (2010), available online at http:/ / hdl.handle.net/1880/48199 [accessed 29 November 2017].

36. Hinrichs and Carpendale, "Gestures in the Wild," 3023-32, doi:10.1145/1978942.1979391. 
and knowledge of materials, and scholars with their deep subject knowledge. The touch table builds an additional collaborative element into the exhibition process, and the availability of adding an interactive digital component to an exhibition has been cited by at least two McGill professors as a particular inducement to partner with the library on an exhibition. The touch table in the case of McGill has provided another piece of common ground on which librarians and faculty can meet, moving toward a collaborative relationship and beyond a purely service orientation. $^{37}$

\section{Conclusion}

Exhibitions programming plays an important role in the life of special collections libraries. It aids in collections promotion and discovery, plays a role in student outreach and learning, and also encourages the creation or communication of new scholarship. Setting out to acquire a touch table for varied use in the library, McGill special collections librarians rapidly realized the benefit of the technology to library-based exhibitions, namely being able to showcase more materials in an array of formats (improving our ability to exhibit, for example, music special collections material), display greater amounts of materials (of particular interest in a library where space is always at a premium and exhibition spaces are not large), allow for a greater range of curatorial choices, and engage viewers in new ways. We also encountered a set of challenges that many libraries must certainly be able to relate to: lack of programmer time available and budget for the creation of custom digital exhibitions, and the need to create professional-level experiences without impinging too much on librarians' already busy schedules. IntuiFace software was discovered to be the answer to these issues and has enabled librarian curators to create attractive and user-friendly touch table experiences without the need to invest too much time or budget. In addition to testing software and figuring out what we considered to be most adapted to librarians' needs and the library setting, we also uncovered various lessons, some of which have become part of our model of practice, such as sharing tables and experiences between branch libraries and using the technology as a point of faculty/student and librarian collaboration, and others, such as the role played by screen positioning, which still require reflection and experimentation.

37. This idea of emphasizing a collaborative model between librarians and faculty is found in some library and information literature with regard to instruction in particular; see, for example, Yvonne Nalani Meulemans and Allison Carr, "Not at Your Service: Building Genuine Faculty Librarian Partnerships," Reference Services Review 41, no. 1 (2013): 80-90, doi:10.1108/00907321311300893. 